\title{
Thermokinetic study of the isomerization of isocyanic acid
}

\author{
Nguyen Huu Tho \\ Sai Gon University \\ Received 7 December 2016; Accepted for publication 28 August 2017
}

\begin{abstract}
In this work, the detailed study on the mechanism, kinetics and thermochemistry of the isomerization of isocyanic is described. Theoretical study was carried out by ab initio molecular orbital theory based on the CCSD(T) and B3LYP/6-311++G(3df,2p) methods in conjunction with statistical theoretical kinetic Rice-Ramsperger-KasselMarcus (RRKM) Master equation calculations. The potential energy surface (PES) for the isomeric reactions was also examined. At 760 Torr pressure, temperature dependent rate constants of the isomeric reactions $\mathrm{HNCO} \rightarrow \mathrm{HOCN}$ (a), $\mathrm{HNCO} \rightarrow \mathrm{H}(\mathrm{CNO})$ (b) and $\mathrm{HNCO} \rightarrow \mathrm{H}(\mathrm{NCO})$ (c) were: $\mathrm{k}(\mathrm{T})$ (a) $=10^{-37.70} \cdot \mathrm{T}^{13.09} \cdot \mathrm{e}^{-93.30 \mathrm{kcal} / \mathrm{mol} / \mathrm{RT}}, \mathrm{k}(\mathrm{T})$ (b) $=$ $10^{3.46} \cdot \mathrm{T}^{1.76} \cdot \mathrm{e}^{-93.98 \mathrm{kcal} / \mathrm{mol} / \mathrm{RT}}, \mathrm{k}(\mathrm{T})(\mathrm{c})=10^{-28.50} \cdot \mathrm{T}^{10.61} \cdot \mathrm{e}^{-91.16 \mathrm{kcal} / \mathrm{mo} / \mathrm{RT}}$ respectively. Calculated results show that the isomerization of isocyanic acid may take place via three mechanisms and have very high barriers; all rate constants of them are very small in the temperature range from 300 to $2000 \mathrm{~K}$.
\end{abstract}

Keywords. Potential energy surface, isocyanic acid, density function theory, isomerization.

\section{INTRODUCTION}

Isocyanic acid (HNCO) is known as the simplest organic compound which has full four most important biogenic elements $\mathrm{C}, \mathrm{H}, \mathrm{N}, \mathrm{O}$ in organic chemistry. This molecule has sixteen valence electrons, symmetric group $C_{S}$. Its electronic configuration in ground state is given by $\left(1 a^{\prime}\right)^{2}\left(2 a^{\prime}\right)^{2}\left(3 a^{\prime}\right)^{2}\left(4 a^{\prime}\right)^{2}\left(5 a^{\prime}\right)^{2}\left(6 a^{\prime}\right)^{2}\left(7 a^{\prime}\right)^{2}\left(1 a^{\prime \prime}\right)^{2}\left(8 a^{\prime}\right)^{2}($ $\left.9 a^{\prime}\right)^{2}\left(2 a^{\prime \prime}\right)^{2}\left(10 a^{\prime}\right)^{0}[1,2]$. In daily life, the major source forming isocyanic acid is from tobacco smoke, biomass burning, fuel burning at low temperature, forest fires, etc. At concentration over 1 ppbv (parts per billion by volume), isocyanic acid can cause cataract, heart failure and other chronic diseases efor example rheumatoid arthritis [3]. Isocyanic acid is also formed from dissociative photoionization reaction of urea [4].

$\mathrm{CO}\left(\mathrm{NH}_{2}\right)_{2}+\mathrm{hv} \rightarrow \mathrm{NH}_{3}{ }^{+}+\mathrm{HNCO}+\mathrm{e}$

Fulminic acid (iosomer of isocyanic acid) plays an important role in the combustion chemistry due to its involvement in the NO-reburning process for the reduction of $\mathrm{NO}_{\mathrm{x}}$ pollutants. It is also one of the components of photochemical smog. Fulminic acid is formed primarily by the combustion of fossil fuels whose normal products include water vapor, $\mathrm{CO}_{2}$ and some pollutant gas such as $\mathrm{CO}$, and $\mathrm{NO}_{\mathrm{x}},[3,5$, $6]$. Therefore, the understanding of the isomerization of $\mathrm{HNCO}$ isomers has particular significance for environmental research.

The study on the HNCO isomerization were performed firstly by Dieter Poppinger et al. in 1976 by using Roothaan' method with STO-3G, 4-31G, and $6-31 \mathrm{G}^{*}$ basis sets. Seven minima found on the potential energy surface is isocyanic acid, cyanic acid, fulminic acid, isofulminic acid, formylnitrene, oxazirine, and oxaziridinylidene. However, the structures of formylnitrene, oxazirine were only found at very small STO-3G basis set, with a larger basis set these structures did not exist. In addition, this potential energy surface was not indicated fully. The HCON and HNOC isomers had not been mentioned on the potential energy surface [7]. Recently, some of the properties of electrons and magnetic properties of four stable isomers including isocyanic acid, cyanic acid, fulminic acid, and isofulminic acid were also studied in the ground state [8-10]. On the other hand, the kinetics of the isomerization of $\mathrm{HCN}, \mathrm{CH}_{3} \mathrm{NC}$ had been studied [11-14] but without any kinetics of isocyanic acid isomerization. A full theoretical study on the potential energy surface of the isomerization at higher level as well as their kinetics is very necessary.

\section{COMPUTATIONAL METHODS}

Geometric optimizations for the eight isomers and ten 
transition states (TS) were carried out at the B3LYP level of density functional theory (DFT) using the 6$311++\mathrm{G}(3 \mathrm{df}, 2 \mathrm{p})$ basis set. The vibrational frequencies of the transition state were calculated at the same level. The symbol TS $\mathbf{i} / \mathbf{j}$ is used to denote the transition state connecting isomers (i) and (j). All of the stationary points were confirmed to be local minima or transition states by harmonic vibrational analysis. Single point energy (SP) calculations of all species were performed at the $\operatorname{CCSD}(\mathrm{T}) / 6$ $311++G(3 d f, 2 p)$ level using the B3LYP/6$311++\mathrm{G}(3 \mathrm{df}, 2 \mathrm{p})$ optimized geometries. Natural bond orbital (NBO) analysis was calculated at HF/STO-3G level. All calculations were carried out using the GAUSSIAN-03 program packages [15].

The thermodynamic parameters and vibrational frequencies that were scaled down by 0.989 [16] were used to calculate kinetic by using RRKM theory and ChemRate program $[17,18]$. This is the RRKM formula:

$$
k(T)=\frac{\sigma}{h Q(T)} \int_{E_{0}}^{\infty} \frac{N^{\ddagger}\left(E-E_{0}\right) e^{-E / k_{B} T}}{1+k(E) / \omega} d E
$$

where $k(T)$ is the rate constant, $T$ is the temperature, $h$ is Plank's constant, $k_{B}$ is Boltzmann's constant, $\sigma$ is the reaction symmetry factor, $Q$ is the partition function, $E$ is the reactant internal energy, $E_{0}$ is the critical energy of the reaction, $N^{*}$ is the sum of the TS states, $\omega$ is the collisional frequency, $k(E)$ is the microcanonical rate constant.

The Lennard-Jone parameters for $\mathrm{HNCO}$ isomers and Ar bath gas were: $\sigma_{\mathrm{HNCO}}=4.42 \AA$, $\varepsilon_{\mathrm{HNCO}}$ $=258 \mathrm{~K}, \sigma_{\mathrm{Ar}}=3.47 \AA, \varepsilon_{\mathrm{Ar}}=116 \mathrm{~K}$ [19]. In the present work, temperature was taken in the range from 300-3000 K, at 760 Torr Ar pressure.

\section{RESULTS AND DISCUSSION}

\subsection{Potential energy surface}

Figure 1 depicts the structures of isomers and transition states. All structures have singlet electronic ground state. Isocyanic acid, HNCO has the lowest relative energy $\left(\mathrm{E}_{\mathrm{rel}}\right)$ among all $\mathrm{CHNO}$ isomers on potential energy surface $(\mathrm{PES})[\mathrm{H}, \mathrm{C}, \mathrm{N}$, $\mathrm{O}$ ]. Cyanic acid, fulminic acid and isofulminic acid lie respectively, 25.03, 69.21 and $83.41 \mathrm{kcal} / \mathrm{mol}$ higher in energy than isocyanic acid. Our results agree well with the previous study results of Michael S. Schuurman that are 24.7, 70.7 and $84.1 \mathrm{kcal} / \mathrm{mol}$ respectively [20]. The four acid isomers above have the lowest relative energy on the PES. Therefore, they are the most stable isomers. Isofulminic acid (HONC) is the least stable of the four acid isomers. These are in good agreement with Dieter Poppinger' prediction [7]. The oxaziridinylidene $\mathrm{H}(\mathrm{NCO})$ (6) structure is a three-membered ring, relative energy of which is $105.84 \mathrm{kcal} / \mathrm{mol}$. The oxazirine $\mathrm{H}(\mathrm{CNO})$ (5) structure is also a three-membered ring. Its relative energy is nearly $2 \mathrm{kcal} / \mathrm{mol}$ higher than isofulminic acid. We also established the reaction pathway for the structure (7) that was predicted but not finished by Dieter Poppinger [7].

Analyzing NBO at HF/STO-3G level shows that in the $\mathrm{N}-\mathrm{O}$ bond of (7) structure, the distribution of $\mathrm{O}$ atom is $84.05 \%$, only $15.95 \%$ for $\mathrm{N}$ atom. This means that the structure (7) is very similar to a complex compound which contains a $\mathrm{N} \leftarrow \mathrm{O}$ donor acceptor bond. This $\mathrm{N} \leftarrow \mathrm{O}$ bond length is $1,47 \AA$ (figure 1) longer than a normal $\mathrm{N}-\mathrm{O}$ bond length. Therefore, the (7) structure is unstable, ready to go $(\mathrm{CO}+\mathrm{NH})$ formation. This suggested a new pathway for forming $(\mathrm{CO}+\mathrm{NH})$ : fulminic acid $\rightarrow \mathrm{TS} 6 / 3 \rightarrow$ oxaziridinylidene $\rightarrow$ TS6/7 $\rightarrow$ HNOC $\rightarrow$ (NH + $\mathrm{CO})$. The data in figure 1 show that barriers of this pathway are not much higher than the barriers of the path recommended by J. K. Yu group, fulminic acid $\rightarrow \mathrm{TS} 5 / 3 \rightarrow \mathrm{H}(\mathrm{CNO}) \rightarrow \mathrm{TS} 1 / 5 \rightarrow \mathrm{HNCO} \rightarrow \mathrm{TS} \rightarrow$ $(\mathrm{NH}+\mathrm{CO})$ when they studied the photolysis of fulminic acid at $248 \mathrm{~nm}$ ultraviolet wavelength [21].

With the acyclic compound (8) - HCON, it was predicted and optimized at STO-3G level by Dieter Poppinger et al. [7] but not successfully at higher basis set due to converting to (1), (2) or (4). We optimized successfully (8) with a very large 6$311++\mathrm{G}(3 \mathrm{df}, 2 \mathrm{p})$ basis set, which is also the minimum has the highest relative energy on the PES, thus, the viability of $\mathbf{( 8 )}$ isomer is very small at low temperature.

As mentioned in the preceding section, the three lowest relative energy structures including isocyanic acid, cyanic acid and fulminic acid have very high barrier in isomeric reactions. The isomerization of isocyanic acid has three mechanisms, either via TS $\mathbf{1 / 2}$ $(140.58 \mathrm{kcal} / \mathrm{mol})$ to form cyanic acid, or via TS $\mathbf{1 / 5}$ $(106.37 \mathrm{kcal} / \mathrm{mol})$ to form $(\mathbf{5})(85.3 \mathrm{kcal} / \mathrm{mol})$, or via TS $\mathbf{1} / \mathbf{6}(129.41 \mathrm{kcal} / \mathrm{mol})$ to form $(\mathbf{6})(105.84 \mathrm{kcal} / \mathrm{mol})$. Among these mechanisms, the one via TS 1/5 with the lowest barrier will occur in the easiest way. For cyanic acid $(25.03 \mathrm{kcal} / \mathrm{mol})$, there are only two isomeric mechanisms, via TS $\mathbf{1 / 2}$ to come back isocyanic acid or via TS $2 / 4(109.89 \mathrm{kcal} / \mathrm{mol})$ to form isofulminic acid $(83.41 \mathrm{kcal} / \mathrm{mol})$. Likewise, fulminic acid (69.21 $\mathrm{kcal} / \mathrm{mol}$ ) also has only two isomeric mechanisms, via TS $\mathbf{6 / 3}(136.10 \mathrm{kcal} / \mathrm{mol})$ to form (6) or via TS $\mathbf{5 / 3}$ $(137.21 \mathrm{kcal} / \mathrm{mol})$ to form (5). The data on PES in figure 1 show that all isomerizations will have to overcome very high barriers. Therefore, the isomeric ability of (1), (2), (3) is impossible under normal 
condition. The quantitative result of these processes will be considered further at the later kinetic section.

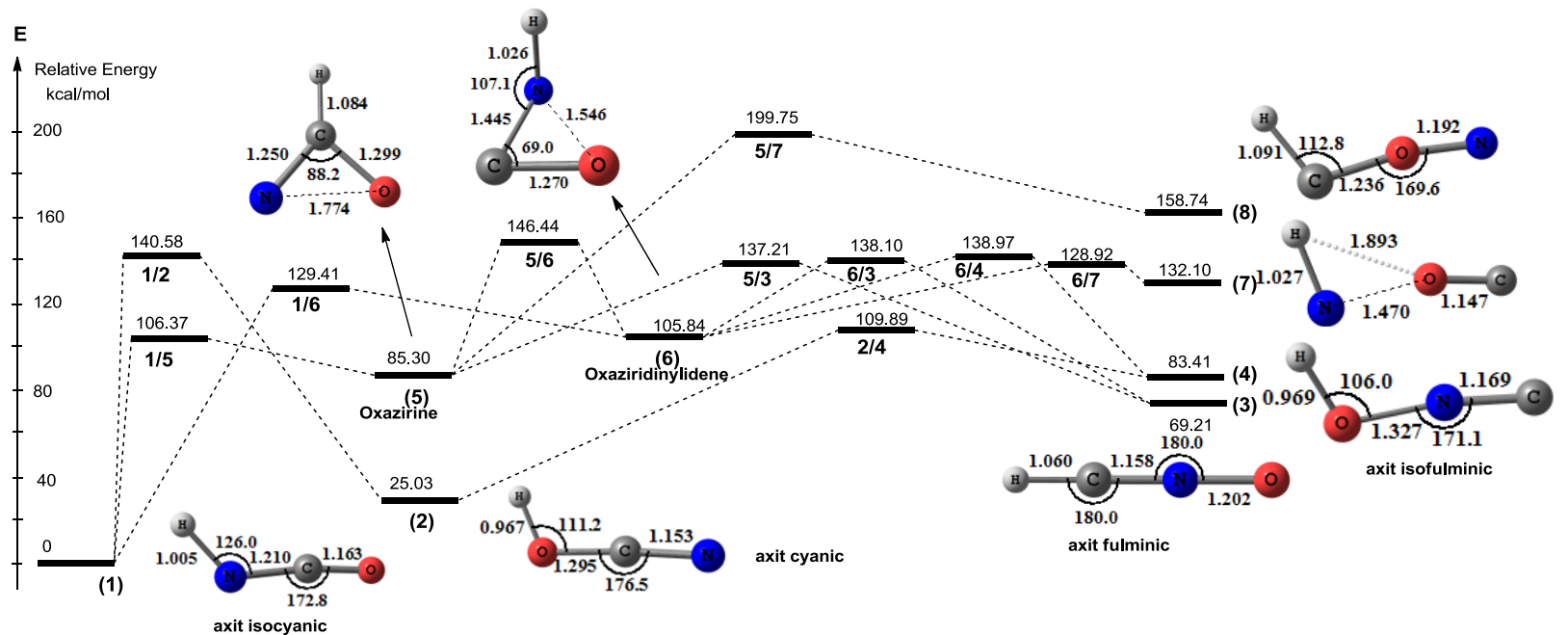

Figure 1: Detailed PES $\left(\mathrm{kcal}^{\mathrm{mol}}{ }^{-1}\right)$ of the isomers $[\mathrm{H}, \mathrm{C}, \mathrm{N}, \mathrm{O}]$ obtained at the $\mathrm{CCSD}(\mathrm{T}) / 6-311++\mathrm{G}(3 \mathrm{df}, 2 \mathrm{p})$ level of theory. The optimized geometries at the B3LYP/6-311++G(3df,2p). Bond distances in $(\AA)$, bond angles in degrees

Table 1: ZPE, SP (a.u.), $\mathrm{E}_{\mathrm{rel}}, \Delta \mathrm{H}_{\mathrm{f}}^{0} 0 \mathrm{~K}, \Delta \mathrm{H}_{\mathrm{f}}^{0} 298 \mathrm{~K}(\mathrm{kcal} / \mathrm{mol})$ of isomers and transition states

\begin{tabular}{|c|c|c|c|c|c|}
\hline Species & ZPE & SP & $\mathrm{E}_{\text {rel }}$ & $\Delta \mathrm{H}_{\mathrm{f} 0 \mathrm{~K}}^{0}$ & $\Delta \mathrm{H}_{\mathrm{f} 298 \mathrm{~K}}^{0}$ \\
\hline $\begin{array}{l}\text { (1) } \mathrm{HNCO} \\
\text { Isocyanic acid }\end{array}$ & 0.021327 & -168.434757 & 0.00 & $\begin{array}{lc} & -27.99 \\
(-27.9 \pm 1) & {[16]} \\
-(27.8 \pm 0.3) & {[4]}\end{array}$ & $\begin{array}{cc} & -28.74 \\
\geq(-27.7 \pm 1.1) & {[22]} \\
(-27.8 \pm 0.4) & {[23]} \\
(-28.5 \pm 0.3) & {[4]}\end{array}$ \\
\hline $\begin{array}{l}\text { (2) } \mathrm{HOCN} \\
\text { Cyanic acid }\end{array}$ & 0.021568 & -168.3951152 & 25.03 & -3.12 & $\begin{array}{c}-3.80 \\
(-3.55 \pm 0.24)[24]\end{array}$ \\
\hline $\begin{array}{c}\text { (3) HCNO } \\
\text { Fulminic acid }\end{array}$ & 0.019933 & -168.3230662 & 69.21 & 42.09 & $\begin{array}{c}41.63 \\
(40.26 \pm 0.29)[24]\end{array}$ \\
\hline $\begin{array}{c}\text { (4) HONC } \\
\text { Isofulminic acid }\end{array}$ & 0.020368 & -168.3008765 & 83.41 & 56.02 & $\begin{array}{c}55.58 \\
(55.72 \pm 0.24)[24]\end{array}$ \\
\hline $\begin{array}{l}\text { (5) } \mathrm{H}(\mathrm{CNO}) \\
\text { Oxazirine }\end{array}$ & 0.019896 & -168.2973992 & 85.30 & 58.20 & 57.40 \\
\hline $\begin{array}{c}\text { (6) } \mathrm{H}(\mathrm{NCO}) \\
\text { Oxaziridinylidene }\end{array}$ & 0.019567 & -168.2643246 & 105.84 & 78.96 & 78.13 \\
\hline (7) $\mathrm{HNOC}$ & 0.017903 & -168.2208136 & 132.10 & 106.26 & 105.93 \\
\hline (8) HCON & 0.018257 & -168.1787261 & 158.74 & 132.67 & 131.99 \\
\hline $5 / 6$ & 0.014168 & -168.1942293 & 146.44 & 122.94 & 122.14 \\
\hline $6 / 3$ & 0.017783 & -168.2111434 & 138.10 & 112.33 & 111.41 \\
\hline $2 / 4$ & 0.018603 & -168.2569079 & 109.89 & 83.61 & 82.81 \\
\hline $1 / 5$ & 0.016805 & -168.2607305 & 106.37 & 81.21 & 80.28 \\
\hline $1 / 2$ & 0.013512 & -168.2029086 & 140.58 & 117.49 & 116.75 \\
\hline $5 / 3$ & 0.015893 & -168.2106653 & 137.21 & 112.63 & 111.86 \\
\hline $1 / 6$ & 0.017175 & -168.2243748 & 129.41 & 104.02 & 103.13 \\
\hline $5 / 8$ & 0.014591 & -168.1096919 & 199.75 & 175.99 & 175.35 \\
\hline $6 / 7$ & 0.015236 & -168.2232176 & 128.92 & 104.75 & 104.52 \\
\hline $6 / 4$ & 0.014664 & -168.2066894 & 138.93 & 115.12 & 114.36 \\
\hline
\end{tabular}




\subsection{Thermodynamic properties}

By spectroscopy techniques, in 1995, Zhang et al. detemined the heat of formation of isocyanic acid $\Delta \mathrm{H}_{\mathrm{f} \text { K }}^{0}(\mathrm{HNCO}, \mathrm{g})=-(27.9 \pm 1.0) \mathrm{kJ} \cdot \mathrm{mol}^{-1}$ [16]. In 1996, Steven S. Brown and coworkers via calculation the $\mathrm{N}-\mathrm{H}$ and $\mathrm{C}-\mathrm{O}$ binding energy of $\mathrm{HNCO}$ molecule gave $\Delta \mathrm{H}_{\mathrm{f}}^{0}(\mathrm{HNCO}, \mathrm{g}) \geq-(27.7 \pm 1.1)$ kcal.mol ${ }^{-1}$ [22]. Also in 1996, M. Zyrianov et al. using photodissociation specified $\Delta \mathrm{H}_{\mathrm{f}}^{0}(\mathrm{HNCO}, \mathrm{g})=$ $-27.8 \pm 0.4 \mathrm{kcal}^{\mathrm{mol}}{ }^{-1}$ [23]. Most recently, in 2013, Andras Bodi et al. using dissociative photoionization technology reported $\Delta \mathrm{H}_{\mathrm{f} \text { } \mathrm{K}}^{0}(\mathrm{HNCO}$, $\mathrm{g})=-(27.8 \pm 0.3) \mathrm{kcal} \cdot \mathrm{mol}^{-1}, \Delta \mathrm{H}_{\mathrm{f}}^{0}(\mathrm{HNCO}, \mathrm{g})=$ $-(28.5 \pm 0.3) \mathrm{kcal}^{\mathrm{mol}}{ }^{-1}$ [4]. Comparing with heat of formation reported previously, our theoretical result $\Delta \mathrm{H}_{\mathrm{f} 0 \mathrm{~K}}^{0}(\mathrm{HNCO}, \mathrm{g})=-27.99 \mathrm{kcal} \cdot \mathrm{mol}^{-1}, \Delta \mathrm{H}_{\mathrm{f}}^{0}(\mathrm{HNCO}$, $\mathrm{g})=-28.74 \mathrm{kcal} . \mathrm{mol}^{-1}$ are in good agreement. As shown in table 1 , the heat of formation values of cyanic acid, fulminic acid, isofulmic acid are also not much different with experimental values. Remarkably, only heat of formation of isocyanic and cyanic acid are negative. These are also energetically lowest lying iosmers on PES. Therefore, they are the stablest isomers. Whereas, fulminic acid and isofulminic acid, their heat of formation and relative energy are much higher. The results of calculation Gibbs free energy for three isocyanic acid isomeric reactions:

$\mathrm{HNCO} \rightarrow \mathrm{HOCN} \quad$ (a) $\Delta \mathrm{G}_{298 \mathrm{~K}}^{0}=24.88 \mathrm{kcal} / \mathrm{mol}$

$\mathrm{HNCO} \rightarrow \mathrm{H}(\mathrm{CNO})$ (b) $\Delta \mathrm{G}^{0}{ }_{298 \mathrm{~K}}=84.74 \mathrm{kcal} / \mathrm{mol}$

$\mathrm{HNCO} \rightarrow \mathrm{H}(\mathrm{NCO})\left(\right.$ c) $\Delta \mathrm{G}^{0}{ }_{298 \mathrm{~K}}=105.35 \mathrm{kcal} / \mathrm{mol}$

At standart condition, Gibbs free energy $\left(\Delta \mathrm{G}^{0}{ }_{298 \mathrm{~K}}\right)$ of the reactions $(\mathrm{a}, \mathrm{b}, \mathrm{c})$ are quite positive. Hence, (a), (b) and (c) are likely not to occur at 298 $\mathrm{K}$ thermodynamically.

\subsection{Rate constant}

In order to test the validity of the present ab initio chemical kinetic predictive approach by RRKM calculations, we have computed the rate constant for the $\mathrm{CH}_{3} \mathrm{NC} \rightarrow \mathrm{CH}_{3} \mathrm{CN}$ isomeric reaction. The result in table 2 showed that obtained theoretical rate constant $\mathrm{k}=5.88 \times 10^{-4}\left[\mathrm{~s}^{-1}\right]$ at $\mathrm{T}=500 \mathrm{~K} ; \mathrm{P}=13 \mathrm{bar}$ was in good agreement with experimental values. Thus, using the $\operatorname{CCSD}(\mathrm{T}) / \mathrm{B} 3 \mathrm{LYP} / 6-$ $311++\mathrm{G}(3 \mathrm{df}, 2 \mathrm{p})$ methods in conjunction with statistical theoretical kinetic RRKM Master equation calculations is very appropriate for computing kinetics of the isomerizations.

Table 2: Rate constant $\mathrm{k}(\mathrm{T})\left[\mathrm{s}^{-1}\right]$ at $500 \mathrm{~K}$ of the reaction $\mathrm{CH}_{3} \mathrm{NC} \rightarrow \mathrm{CH}_{3} \mathrm{CN}$

\begin{tabular}{|c|c|c|c|c|}
\hline \multirow{3}{*}{$\mathrm{T}(\mathrm{K})$} & \multicolumn{4}{|c|}{$\mathrm{k}(\mathrm{T})\left[\mathrm{s}^{-1}\right]$} \\
\cline { 2 - 5 } & $\begin{array}{c}2.67 \mathrm{E}-3-0.13 \\
\text { Bar }\end{array}$ & $\begin{array}{c}1.33 \mathrm{E}-3-13.33 \\
\text { Bar }\end{array}$ & $\begin{array}{c}\text { Infinite } \\
\text { pressure }\end{array}$ & $\begin{array}{c}13.00 \\
\text { Bar }\end{array}$ \\
\hline 500 & $4.71 \mathrm{E}-4$ & $6.86 \mathrm{E}-4$ & $7.81 \mathrm{E}-4$ & $5.88 \mathrm{E}-04$ \\
\hline Literature & {$[11]$} & {$[12]$} & {$[13]$} & This work \\
\hline
\end{tabular}

Table 3: Rate constant $\mathrm{k}(\mathrm{T})\left[\mathrm{s}^{-1}\right]$ in the temperature range $2100-3000 \mathrm{~K}$ of the HNCO isomeric reactions

\begin{tabular}{|c|c|c|c|c|c|c|c|}
\hline $\mathrm{T}(\mathrm{K})$ & $\mathrm{k}_{(1 \rightarrow \mathrm{TS} 1 / 2)}$ & $\mathrm{k}_{1 \rightarrow \mathrm{TS} 1 / 5}$ & $\mathrm{k}_{1 \rightarrow \mathrm{TS} 1 / 6}$ & $\mathrm{~T}(\mathrm{~K})$ & $\mathrm{k}_{(1 \rightarrow \mathrm{TS} 1 / 2)}$ & $\mathrm{k}_{1 \rightarrow \mathrm{TS} 1 / 5}$ & $\mathrm{k}_{1 \rightarrow \mathrm{TS} 1 / 6}$ \\
\hline 2100 & 0.000122 & 0.347449 & 0.001927 & 2600 & 0.146886 & 38.50341 & 1.241308 \\
\hline 2200 & 0.000618 & 1.049844 & 0.008524 & 2700 & 0.469952 & 80.72601 & 3.561637 \\
\hline 2300 & 0.002798 & 2.891444 & 0.033826 & 2800 & 1.407905 & 160.9078 & 9.612161 \\
\hline 2400 & 0.011436 & 7.342240 & 0.122000 & 2900 & 3.974057 & 306.4966 & 24.54340 \\
\hline 2500 & 0.042683 & 17.35576 & 0.404186 & 3000 & 10.62645 & 560.4015 & 59.59463 \\
\hline
\end{tabular}

The predicted rate constants of the $(\mathrm{a}, \mathrm{b}, \mathrm{c})$ isomeric reactions given in units of $\mathrm{s}^{-1}$ at 760 Torr Ar pressure in the temperature range $300-3000 \mathrm{~K}$ can be represented by:

$$
\begin{aligned}
& \mathrm{k}(\mathrm{T})(\mathrm{a})=10^{-37.70} \cdot \mathrm{T}^{13.09} \cdot \mathrm{e}^{-93.30 \mathrm{kcal} / \mathrm{mol} / \mathrm{RT}}, \\
& \mathrm{k}(\mathrm{T})(\mathrm{b})=10^{3.46} \cdot \mathrm{T}^{1.76} \cdot \mathrm{e}^{-93.98 \mathrm{kcal} / \mathrm{mol} / \mathrm{RT},} \\
& \mathrm{k}(\mathrm{T})(\mathrm{c})=10^{-28.50} \cdot \mathrm{T}^{10.61} \cdot \mathrm{e}^{-91.16 \mathrm{kcal} / \mathrm{mol} / \mathrm{RT}} .
\end{aligned}
$$

The specific values of rate constants of three above isomeric reactions at different temperature in table 3 and figure 2 showed that it was very difficult for the isomeric reactions to occur in the temperature range $300-2000 \mathrm{~K}$. The reactions only occur considerably at $\mathrm{T}>2000 \mathrm{~K}$ and the direction of forming $\mathrm{H}(\mathrm{CNO})$ oxazirine three-membered ring isomer via transition state TS $\mathbf{1 / 5}$ is more favorable. 


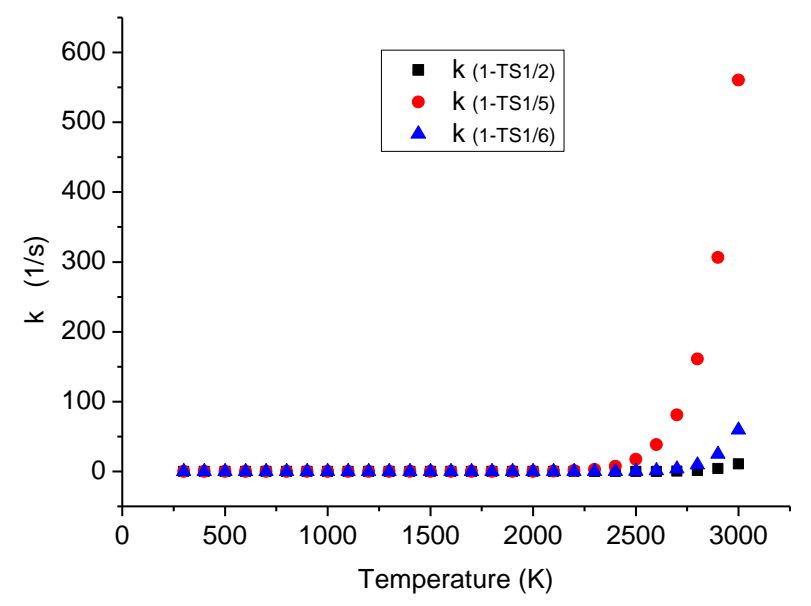

Figure 2: Temperature dependence of rate constants of the $\mathrm{HNCO}$ isomeric reactions

\section{CONCLUSION}

There are eight existent feasible isomers on the potential energy surface $[\mathrm{H}, \mathrm{N}, \mathrm{C}, \mathrm{O}]$, in which isocyanic acid and cyanic acid are the most stable isomers. The HNOC isomer contains a $\mathrm{N} \leftarrow \mathrm{O}$ unstable donor - acceptor bond is intermediate complex forming $\mathrm{CO}, \mathrm{NH}$ products. Isomerizations are difficult to occur at normal temperature and pressure condition. Isomerization isocyanic acid is easier above $2000 \mathrm{~K}$ and favorable to generate $\mathrm{H}(\mathrm{CNO})$ ring compound before forming the other isomer products.

\section{REFERENCES}

1. M. Mladenovic, M. Elhiyani, M. Lewerenz, Marius. Electric and magnetic properties of the four most stable $C H N O$ isomers from ab initio $\operatorname{CCSD}(T)$ studies, J. Chem. Phys., 131, 034302 (2009).

2. J.S. Zhang, M. Dulligan, C. Wittig. HNCO + h.nu.(193.3 nm).fwdarw. $H+$ NCO: Center-of-Mass Translational Energy Distribution, Reaction Dynamics, and DO(H-NCO), J. Phys. Chem., 99, 7446-7452 (1995).

3. J. M. Roberts, P. R. Veres, A. K. Cochran, C. Warneke, I. R. Burling, R. J. Yokelson, B. Lerner, J. B. Gilman, W. C. Kuster, R. Fall and Joost de Gouw. Isocyanic acid in the atmosphere and its possible link to smoke-related health effects, Proceedings of the National Academy of Sciences of the United States of American, 108(22), 8966-8971 (2011).

4. A. Bodi, P. Hemberger, T. Gerber, A robust link between the thermochemistry of urea and isocyanic acid by dissociative photoionization, J. Chem. Thermodynamics, 58, 292-299 (2013).

5. A. L. East, C. S. Johnson and W. D. Allen,
Characterization of the $X^{1} A^{\prime}$ 'state of isocyanic acid, J. Chem. Phys., 98(2), 1299-1328 (1993).

6. Yan Li, Hui-ling Liu, Yan-bo Sun, Zhuo Li, Xu-ri Huang, Chia-chung Sun. Radical reaction $\mathrm{HCNO}+$ ${ }^{3}$ NH: a mechanistic study, Theor. Chem. Acc., 124, 123-137 (2009).

7. D. Poppinger, L. Radom, and J. A. Pople. Theoretical Study of the CHNO Isomers, J. Am. Chem. Soc., 99(24), 7806-7816 (1977).

8. M. Mladenovic, M. Lewerenz, M. C. McCarthy, P. Thaddeus. Isofulminic acid, HONC: Ab initio theory and microwave spectroscopy, J. Chem. Phys., 131, 174308 (2009).

9. Donghui Quan, Eric Herbst, Yoshihiro Osamura, and Evelyne Roueff. Gas-grain Modeling of Isocyanic Acid (HNCO), Cyanic Acid (HOCN), Fulminic Acid (HCNO), and Isofulminic Acid (HONC) in Assorted Interstellar Environments, The Astrophysical Journal, 725, 2101-2109 (2010).

10. M. Mladenovic and M. Lewerenz. Equilibrium structure and energetics of CHNO isomers: steps towards ab initio rovibrational spectra of quasilinear molecules, Chemical Physics, 343, 129-140 (2008).

11. J. L. Collister, H. O. Pritchard. The Thermal Isomerisation of Methyl Isocyanide in the Temperature Range 120-320 ${ }^{\circ} \mathrm{C}$, Can. J. Chem., 54, 2380-2384 (1976).

12. F. W. Schneider, B. S. Rabinovitch. The thermal unimolecular isomerization of methyl isocyanide. Fall-off behavior, J. Am. Chem. Soc., 20, 4215-4230 (1962).

13. M. E. Clarkson, H. O. Pritchard. Partial state-to-state calculation of the infinite-pressure rate constant for the isomerisation of methyl isocyanide, J. Chem. Phys., 117, 29-37 (1987).

14. M. C. Lin, Y. He, F. Melius. Communication: implications of the HCN $\rightarrow$ HNC process to hightemperature nitrogen-containing fuel chemistry, Int. J. Chem. Kinet., 24, 1103-1107 (1992).

15. M. J. Frisch et al. Gaussian 03, revision E.01, Gaussian Inc.: Wallingford, CT (2004).

16. C. J. Cramer. Essentials of Computational Chemistry: Theories and Models, John Wiley \& Sons Ltd, (2004).

17. T. Baer, W. L. Hase. Unimolecular Reaction Dynamics: Theory and Experiments, Oxford, New York (1996).

18. V. Mokrushin, V. Bedanov, W. Tsang, M. R. Zachariah, V. D. Knyazev, W. S. McGivern. ChemRate, version 1.5.8, in: Technology, N.I.o.S.a. (Ed.), Gaithersburg, MD (2011).

19. L. V. Moskaleva and M. C. Lin. The Spin-Conserved Reaction $\mathrm{CH}+\mathrm{N}_{2} \rightarrow \mathrm{H}+\mathrm{NCN}$ : A Major Pathway to Prompt NO Studied by Quantum-Statistical Theory 
Calculations and Kinetic Modeling of Rate Constant, Proc. Combust. Inst., 28, 2393-2401 (2000).

20. M. S. Schuurman, S. R. Muir, W. D. Allen, and H. F. Schaefer. Toward subchemical accuracy in computational thermochemistry: focal point analysis of the heat of formation of NCO and $[H, N, C, O]$ isomers, J. Chem. Phys., 120, 11586-11599 (2004).

21. J. K. Yu, S. Wang, H. Zhang, H. X. Zhang, D. J. Ding, C. C. Sun. Theoretical study on the decomposition mechanism of the HCNO molecules, Acta Chim. Sin., 66, 597-602 (2008).

22. S. S. Brown, H. L. Berghout, and F. F. Crim. The $H N C O$ heat of formation and the $\mathrm{N}-\mathrm{H}$ and $\mathrm{C}-\mathrm{N}$ bond enthalpies from initial state selected photodissociation, J. Chem. Phys., 105, 81038110 (1996).

23. M. Zyrianov, T. Droz-Georget, A. Sanov, and H. Reisler. Competitive photodissociation channels in jet-cooled HNCO: Thermochemistry and nearthreshold predissociation, J. Chem. Phys., 105(18), 8111-8116 (1996).

24. B. Ruscic. Updated Active Thermochemical Tables (ATcT) values based on ver. 1.112 of the Thermochemical Network (2012); available at ATcT.anl.gov; Last update 6/Mar/(2015).

\section{Corresponding author: Nguyen Huu Tho}

Natural Sciences Pedagogy, Sai Gon University

No. 273, An Duong Vuong Str., Ward 3, Dist. 5, Ho Chi Minh City

E-mail: nguyenhuutho04@gmail.com; Telephone: 0983869335. 